\title{
Analyzing The Gap Between Perceptions And Expectations Of Students About The Quality Of Educational Services In Southern Of Iran: Servqual Model
}

\section{Foozieh Rafati}

Jiroft Univercity Of Medical Sciences

\author{
Azizollah Arbabisarjou \\ Zahedan University of Medical Sciences \\ Neda Dastyar ( $\nabla$ nedadastyar98@gmail.com) \\ Jiroft Univercity Of Medical Sciences
}

\section{Research Article}

Keywords: Training, quality of educational services, SERVQUAL model, perceptions, expectations, nursing and midwifery students.

Posted Date: February 1st, 2021

DOI: https://doi.org/10.21203/rs.3.rs-148109/v1

License: (c) (i) This work is licensed under a Creative Commons Attribution 4.0 International License. Read Full License 


\section{Abstract \\ Background}

Universities should be sensitive to the needs and expectations of students. This study aimed to analyze the gap between perceptions and expectations of students of Jiroft University of Medical Sciences about the quality of educational services.

\section{Methods}

This descriptive-analytical study was conducted on 213 medical, nursing, and midwifery students. Census method was used to sampling. The data were collected using a multi-dimensional questionnaire (SERVQUAL-22 items). Finally, the data were analyzed by T-test, ANOVA, and correlation coefficient. the significance level was considered as 0.05 .

\section{Results}

The mean age of the participants in this study was $21.62 \pm 1.79$. Of students $132(62 \%)$ were female and $186(87.3 \%)$ were single. There was a quality gap in all dimensions of the quality of educational services (empathy, reliability, responsiveness, assurance, and tangibility). The highest quality gap was observed in the empathy dimension - 8.66 (4.2) and the smallest gap was observed in the tangibility dimension - 4.18 (4.4). Average score of educational services gap in reliability dimension in terms of education of mothers $(p=0.01)$, and average score of educational services gap in reliability dimension $(p=0.009)$, tangibility dimension $(p=0.015)$ and overall score $(p=0.039)$ in terms of their fathers' education were significant.

\section{Conclusions}

The results indicate that the expectations of the students in all aspects of the quality of educational services (empathy, reliability, responsiveness, assurance, and tangibility) are more than their perceptions. Thus, the authorities must take the necessary measures to meet the expectations of students.

\section{Introduction:}

Attention to the quality of educational services is one of the effective factors in the success and survival of any organization, including the higher education system. The higher education system has both quantitative and qualitative dimensions (1). Attention to quantitative growth and neglect of qualitative growth have dire consequences such as academic failure, scientific dependence, lack of creativity and entrepreneurship, brain drain and inadequate production of science for this system. Given that the educational system plays a vital role in training the specialized and needed human resources of the society that can accelerate the movement of the society towards public development, it is essential to pay attention to the quality of educational services (2). In this regard, medical education is part of the higher education system that deals with human life and the health of society depend on the quality of education in these universities and the lack of appropriate and high-quality programs incurs irreparable damage on the health of the community (3). The concept of quality in education cannot be easily defined. The influence of various factors, including behavioral factors, on the quality of education, has made it very difficult to define and evaluate it (4). Today, it is believed that what are central to the definition of quality are the views of the audience, and the basis of quality depends on the views of the observer. Thus, quality is considered to be the comparison of the customer's expectations (what he feels that should be) with his perceptions (what he has received) (5). As the main clients of higher education, students have attracted the most attention (6). The quality of educational services is determined by examining the gap between students' expectations (optimal status) and their perceptions of the educational services provided (current status). The lower the gap between the 
expectations of students and the educational services provided, the better the quality of the educational services provided (7). Various models have been developed so far for measuring the quality of educational services. One of the most reputable global models used to measure the quality of services is the SERVQUAL model. The SERVQUAL model, or gap analysis model, was developed by Parasuraman et al. in 1985 (8). This model is a multidimensional scale that measures to the quality of service in five dimensions: assurance (meaning the ability of the university to provide the correct and reliable services it promised), responsiveness (meaning helping students to provide services as soon as possible), reliability (meaning the existence of knowledge, politeness and humility and the ability to transfer trust and confidence to students by university staff and instructors), empathy (meaning the ability of university staff and instructors to provide distinctive and caring attention to students), and tangibility (meaning having the necessary physical facilities and equipment) dimensions (9). Based on this model, service receivers (students) evaluate the quality of educational services by comparing their perceptions and expectations of the received services, and the goal of improving the quality of educational services in this model is to minimize the gap between expectations and perceptions. Any action that has the characteristics of meeting the needs of customers is perceived as high quality. Therefore, if the level of expectations is higher than the level of perceptions, the quality of educational services received from the customer's (student's) point of view is weak, leading to dissatisfaction (10). In this model, obtaining feedback from the process customers (students) is one of the basic steps in providing and improving quality and helps identify and prioritize what needs to be improved (11).

Now in Iran, the expansion of universities has been pushed from the quantitative stage to the qualitative stage. Examining and improving the quality of educational services provided is one of the necessities of macro-policies of universities (especially, medical universities). Thus, the presence of a monitoring and evaluation system in the educational system is necessary for determining the strengths and weaknesses, improving the quality of education and training accountable human resources (12). On the other hand, according to the difference between the nature of education, the variety of facilities and equipment and the different staff, faculty members and socio-cultural characteristics of students in different universities, the view of service recipients differs concerning the quality of services and their perceptions of educational services vary. Therefore, by conducting research in any university, the quality of the educational services of that university can be measured and a model with a higher degree of adaptation with the same university can be obtained. On the other hand, considering the importance of the quality of educational services in the fields of medical sciences and the training of efficient staff in these fields (especially, medicine, nursing, and midwifery), the present study was conducted aiming at evaluating the quality of educational services provided at Jiroft University of Medical Sciences in the view of medicine and nursing-midwifery students based on the SERVQUAL model in 2019.

\section{Materials And Methods:}

This study is cross-sectional descriptive-analytical research. The research population included all medical, nursing, and midwifery students of Jiroft University of Medical Sciences Among the majors available at Jiroft University of Medical Sciences, the majors of medicine, nursing, and midwifery were selected due to the long history of the establishment of these majors among other majors. Second- to fourth-year students entered the study as a census. In this study, 245 questionnaires were distributed, which 213 were fully filled out and returned (the response rate was about $87 \%$ ). First-year students, guests, and students transferred from another university were excluded. Data collection tool included a questionnaire consisting of three sections, the first of which covered a demographic information sheet that included information such as age, marital status, gender, the field of study, semester, and mother and father education. The second section was related to the SERVQUAL multi-dimensional questionnaire for measuring the level (quality) of educational services. This questionnaire includes 22 items in 5 dimensions, tangibility (4 items), reliability (5 items), responsiveness (4 items), assurance (4 items), and empathy (5 items). Answer to the questionnaire questions were scored based on the fivepoint Likert scale: very desirable, desirable, moderate, undesirable, very undesirable. For a very desirable choice, a score of 5 , a score of 4 for desirable choice, a score of 3 for moderate choice, a score of 2 for undesirable choice, a score of 1 for and a very undesirable choice. In the end, the scores of all parts are added. The minimum score will be 22 and the 
maximum score will be 110. Third questionnaire: It is the same questionnaire as the second section, but it is for evaluation of the students' expectations from the quality of educational services. The difference between the third questionnaire and the second questionnaire is in Likert scoring, and the student expresses his expectations about the quality of educational services based on the Likert score by selecting the very high (5), high (4), average (3), low (2), and very low (1) scores. To determine the quality gap, firstly, students' views on the current situation (perceptions) and then their view on the desired situation (expectation) were assessed. By deducting the scores of students' expectations from their perceptions, the quality gap of educational services was obtained. A negative score represents a negative gap and a positive score implies a positive gap. This questionnaire has 5 dimensions. The tangibility dimension includes existence of facilities and work equipment and communication goods. The reliability dimension includes the ability to perform services safely and reliably, so that the student's expectations are met. The responsiveness dimension includes the tendency to cooperate and help the student. The assurance dimension includes the competence and ability of employees to instill a sense of trust and confidence in the student towards the organization, and the empathy dimension includes personal attention and allocating appropriate working time for students (13). The validity and reliability of this questionnaire has been confirmed in several foreign and domestic studies. In Iran, in the study of Arab et al. (2011), Cronbach's alpha was obtained as 0.93 for the reliability of the questionnaire for a total of 22 items for the perception of quality, and 93.2 for the expectation of quality (14). After obtaining permission from the university's ethics committee and obtaining permission from the authorities, the researcher went to the School of Medicine and Nursing-Midwifery. Following gaining permission of related authorities and instructors, the SERVQUAL questionnaire in two versions (the first version for measurement of students' perception of current status and a second version for measurement of students' expectations of optimal status) was distributed and collected among students. Then, the difference between students' expectations and perceptions assessed, which is the quality of educational services was measured. The approximate time to complete the questionnaires was about 25 minutes.

\section{Results:}

The mean age of the participants in this study was $21.62 \pm 1.79 .81(38 \%)$ were male and $132(62 \%)$ were female. 186 (87.3\%) were single. 73 participants (34.3\%) were second-year students, 68 (31.9\%) were in the third year and $72(33.8 \%)$ were in the fourth year. There were quality gaps in all dimensions of service. The highest quality gap of educational services was observed in the empathy dimension and then in the reliability, responsiveness, assurance dimensions there was a high gap, and the lowest gap in the quality of educational services was reported in the tangibility dimension (Table 1).

Table 1

Average and standard deviation of expectations, perceptions, and gaps in the quality of educational services

\begin{tabular}{|llll|}
\hline Service Dimensions & The mean (SD) of Perception(P) & The mean (SD) of Expectation(E) & The mean(SD) of P-E \\
\hline Empathy & $13.14(3.5)$ & $21.80(2.4)$ & $-8.66(4.2)$ \\
\hline Reliability & $13.47(3.5)$ & $19.54(3.1)$ & $-6.07(4.4)$ \\
\hline Responsiveness & $11.56(3.1)$ & $17.18(2.3)$ & $-5.62(3.5)$ \\
\hline assurance & $11.88(2.9)$ & $17.31(2.1)$ & $-5.43(3.4)$ \\
\hline tangibility & $12.15(3.2)$ & $16.33(2.9)$ & $-4.18(4.4)$ \\
\hline
\end{tabular}

The results of t-test and ANOVA statistical test showed that the mean score of the gap between the quality of educational services and its domains did not differ significantly in terms of the demographic variables of gender, marital status, semester, and field of study (Table 2). 
Table 2

Mean score of gap in educational service quality and its dimensions in terms of demographic variables

\begin{tabular}{|c|c|c|c|c|c|c|c|}
\hline Variables & & Tangibility & Reliability & Responsiveness & Assurance & Tangibility & Overall \\
\hline \multirow[t]{3}{*}{ sex } & Male & $-3.62(4.2)$ & $-.49(3.9)$ & $-5.49(3.6)$ & $-5.55(3.4)$ & \multirow{2}{*}{$\begin{array}{l}-9.27(3.7) \\
-8.28(4.4)\end{array}$} & $-29.44(12.8)$ \\
\hline & \multirow[t]{2}{*}{ female } & $-4.52(4.5)$ & $-6.4(4.75)$ & $-5.70(3.5)$ & $-5.35(3.5)$ & & $-30.29(15.6)$ \\
\hline & & * & * & * & * & & * \\
\hline \multirow{2}{*}{$\begin{array}{l}\text { Marital } \\
\text { statu }\end{array}$} & Single & \multirow{2}{*}{$\begin{array}{l}-4.29(4.5) \\
-3.44(3.3)\end{array}$} & $-6.02(4.6)$ & $-5.69(3.5)$ & $-5.49(3.5)$ & $-8.84(4.1)$ & $-30.34(14.9)$ \\
\hline & Married & & $-6.40(3.5)^{\star}$ & $-5.14(3.5)$ & $-5.00(3.0)$ & $-7.40(4.6)$ & $-27.40(11.7)$ \\
\hline s & * & * & & * & * & * & * \\
\hline \multirow{4}{*}{$\begin{array}{l}\text { Year of } \\
\text { education }\end{array}$} & 2 & $-4.39(3.8)$ & $-6.0(4.5)$ & $-5.32(3.1)$ & $-5.47(3.0)$ & $-8.87(4.1)$ & \multirow{2}{*}{$\begin{array}{l}-30.13(12.3) \\
-29.61(15.1)\end{array}$} \\
\hline & 3 & $-3.70(4.2)$ & $-6.23(4.5)$ & $-5.79(3.6)$ & $-5.51(3.4)$ & $-8.36(4.4)$ & \\
\hline & \multirow[t]{2}{*}{4} & $-4.41(5.0)$ & $-5.93(4.4)$ & $-5.76(3.8)$ & $-5.30(3.9)$ & $-8.72(4.0)$ & \multirow{2}{*}{$\begin{array}{l}-30.13(16.2) \\
\star\end{array}$} \\
\hline & & * & * & * & * & * & \\
\hline \multirow{4}{*}{$\begin{array}{l}\text { Field of } \\
\text { study }\end{array}$} & Midwifery & $-4.81(4.7)$ & $-5.33(4.5)$ & $-5.54(3.9)$ & $-4.83(3.8)$ & $-7.81(4.5)$ & $-28.3(15.9)$ \\
\hline & Nursing & $-3.70(4.0)$ & $-6.46(4.8)$ & $-5.50(3.0)$ & $-5.75(3.1)$ & $-8.78(3.8)$ & $-30.20(12.0)$ \\
\hline & medicine & $-4.18(4.4)$ & $-6.15(4.7)$ & $-5.91(4.0)$ & $-5.50(3.6)$ & $-9.33(4.3)$ & $-29.97(14.5)$ \\
\hline & & * & * & * & * & * & * \\
\hline \multirow{4}{*}{$\begin{array}{l}\text { mother } \\
\text { education }\end{array}$} & \multirow{2}{*}{$\begin{array}{l}\text { Diploma and } \\
\text { under diploma }\end{array}$} & $-4.21(3.9)$ & $-5.22(4.1)$ & $-5.50(3.4)$ & $-5.14(3.6)$ & $-8.18(4.2)$ & $-28.28(13.6)$ \\
\hline & & $-4.36(4.7)$ & $-7.81(4.6)$ & $-5.91(3.9)$ & $-5.90(3.3)$ & $-9.05(4.3)$ & $-33.05(15.7)$ \\
\hline & Undergr & $-3.83(5.2)$ & $-5.79(4.5)$ & $-5.51(3.5)$ & $-5.51(3.1)$ & $-9.34(3.9)$ & $-30.00(14.9)$ \\
\hline & $\begin{array}{l}\text { Aduate } \\
\text { graduate }\end{array}$ & * & $P=0.01$ & * & * & * & * \\
\hline \multirow{4}{*}{$\begin{array}{l}\text { father } \\
\text { education }\end{array}$} & \multirow{2}{*}{$\begin{array}{l}\text { Diploma and } \\
\text { under diploma }\end{array}$} & $-3.43(4.1)$ & $-5.26(4.6)$ & $-5.47(3.5)$ & $-5.29(3.6)$ & $-8.59(3.9)$ & $-28.04(13.7)$ \\
\hline & & $-5.26(4.5)$ & $-7.22(4.3)$ & $-5.88(3.4)$ & $-5.78(3.3)$ & $-8.95(4.4)$ & $-33.10(15.5)$ \\
\hline & \multirow{2}{*}{$\begin{array}{l}\text { Undergraduate } \\
\text { graduate }\end{array}$} & $-3.65(4.5)$ & $-5.51(3.7)$ & $-5.41(3.8)$ & $-4.89(3.06)$ & $-8.06(4.2)$ & $-29.97(14.5)$ \\
\hline & & $p=0.015$ & $p=0.009$ & * & * & * & $p=0.039$ \\
\hline
\end{tabular}

The mean score of the gap in quality of educational services in reliability dimension in terms of mother education was significant $(p=0.01)$. Tukey's test and Bonferroni correction test showed that the difference in the scores of students whose mothers had a high school diploma or lower and scores of students whose mothers had an undergraduate and graduate degree was significant $(p=0.01)$. Also, the mean score of gap in quality of educational service was significant in dimension of reliability $(p=0.009)$, tangibility $(p=0.015)$ and overall score $(p=0.039)$ in terms of paternal education. Tukey's test and Bonferroni correction test showed that the difference in the score of gap in educational service quality in dimension of reliablity was significant between students whose fathers had a high school diploma or lower and scores of students whose mothers had an undergraduate and graduate degree was significant $(p=0.01)$. Tukey's test and Bonferroni correction test showed that the difference in the score of gap in educational service quality in dimension of tangibility was significant between students whose fathers had a high school diploma or lower and scores of students whose fathers had an undergraduate and graduate degree $(p=0.01)$. The difference in the total score of gap in educational service quality was 
significant between students whose fathers had a high school diploma or lower and scores of students whose fathers had an undergraduate and graduate degree $(p=0.04)$. Besides, the Pearson correlation coefficient showed no significant difference with a total score of educational service quality and its dimensions $(p>0.05)$.

\section{Discussion:}

The results of this study in response to the following questions were conducted: How is the status of the quality of educational services in Jiroft University of Medical Sciences based on the SERVQUAL model? And is there a difference between students' perceptions and expectations of service quality? The results indicated that there was a negative gap in all dimensions of educational service quality (empathy, responsiveness, assurance, reliability, and tangibility). The negative gap indicates that the level of quality of services provided at Jiroft University of Medical Sciences is low and in general, students' expectations are beyond their perceptions of the current situation and in none of the dimensions of service, students' expectations have not been met. The educational service quality in the university in question needs to be upgraded and improved in all dimensions. On the other hand, these results can indicate students' dissatisfaction with the quality of educational services in the studied university, because studies have shown that there is a positive and significant relationship between the quality of educational services and student satisfaction (15).

Results obtained regarding the negative gap among the dimensions of educational service quality are consistent with the results of many domestic and foreign studies, such as Khosravi Zadeh et al. (2017) (16), Yazdani et al. (2018) (17), Jafarinejad et al. (2016) (18), Rahim Khanli et al. (2014) (19), Khandan et al. (2015) (20), Nabiloo et al. (2014) (21), Donlagic et al. (2015) in Bosnia and Herzegovina (22), Asogwa et al. (2014) as well as the studies in four developing countries, including Bangladesh, Iran, Niagara and Pakistan (23) and Bardley et al. (2012) in the United Kingdom (24). A review study in Iran also found that the gap between the quality of educational services in Iranian medical universities is negative one or more dimensions (25). These findings confirm that in most educational settings, less attention is paid to the quality of educational services and the opinions, requests and problems of students who are customers of the educational process are not considered, and students' expectations in various dimensions are beyond the current situation.

In the present study, the highest quality gap of educational services was observed in the empathy dimension and then in the reliability, responsiveness, assurance dimensions there was high gap, and the lowest gap in the quality of educational services was reported in the tangibility dimension. The empathy dimension reflects the university's willingness to provide prompt services to students and represents their sensitivity and awareness of the demands, questions, and complaints raised by students. In addition, the empathy dimension refers to the warmth and well-tempered treatment with students, understanding their specific conditions, and respect for their opinions by employees and instructors. The biggest gap in empathy dimension suggests that students do not have a good mechanism for expressing their opinions and suggestions, their opinions are not considered in curriculum planning, and staff and instructors are not interested in hearing students' opinions, and instructors and educators perceive that their most important role is to convey information and educational content and pay less attention to the communication with students. In this regard, some studies in Iran reported the highest service quality gap in terms of empathy $(26,27,11)$. Also in a study by Kanti $(2020)$ in India, the gap in the quality of educational services was reported as high in empathy dimension (28). But others, contrary to our study results, reported the lowest service quality gap in this dimension $(29,23)$. The negative gap between students' expectations and perceptions in empathy dimension may indicate that instructors and staff are unfamiliar with the skill of empathy in communicating with students. On the other hand, the increase in student enrollment in recent years and the shortage of instructors and staff may lead to a lack of time for staff and instructors to listen emphatically to students (21).

The second negative gap in the quality of educational services was observed in the assurance dimension. Reliability dimension indicates that employees have sufficient knowledge, skills, and the ability to behave confidently. The gap in this dimension shows the lack of sufficient experience and skills in staff and instructors, the limitations of faculty recruitment, the non-fulfillment of promises made to students, the lack of timely provision of educational services and lack of

Page 6/11 
awareness of the results of evaluation and regular courses in students. In a study by Khosravi Zadeh et al. (2017) (16) and Jafarinejad et al. (2017) (18), the lowest gap in the quality of educational services was in the reliability dimension. However, in our study, the gap in reliability dimension is the second priority from the students' point of view.

The third rank of negative gap was reported in the responsiveness dimension. The gap between expectations and perceptions in this dimension shows that the education officials and authorities are not student-centered and have poor relationships with students. Instructors are less available when students need them, and students have to wait a long time to find answers to their questions. In the research of Yazdani et al. (2018) (17), the greatest gap was reported in the responsiveness dimension, which is not consistent with the results of our study.

The fourth negative gap in this study was in the assurance dimension. The findings showed that instructors should facilitate discussion on the subject of the classroom and provide appropriate theoretical and practical training to prepare students for future careers and use modern teaching methods and advanced human knowledge in teaching.

The lowest score of negative gap was seen in the tangibility dimension. This dimension of educational service is especially important for students. The negative gap in this dimension shows that the apparent attractiveness of physical facilities and the apparent attractiveness of the equipment used by professors in education have not been able to fully satisfy students, and the inefficiency of university equipment and the lack of available educational equipment and facilities have made problem for meeting expectations of the majority of students. Lack of needed spaces for studying and resting, library and laboratory, sports grounds and old teaching tools, in other words, not using new methods of e-learning, causes a gap between students' expectations and perceptions in this dimension. The low average gap in the tangibility dimension compared to other dimensions shows that the university pays more attention to physical issues than human relationships. Yasbolaghi et al. (2015) (30), Hematinejad et al. (2014) (29), Asogwa et al. (2014) (23), Gorji et al. (2013) (6), Ghalavandi et al. (2012) (31), Khademloo et al. (2012) (32) and Kanti (2014) (28) in their studies showed the highest quality of educational services in the tangibility dimension, which is inconsistent with the results of this study. However, Najafi et al. (2014) (33), Enayati et al. (2013) (34), Kavousi et al. (2014) (27), as in our study, reported the lowest gap in the quality of educational services in the tangibility dimension.

The difference between the lowest and highest gap in quality of educational services in different universities may be due to the different majors and levels of study, the number of samples (students), physical and educational spaces, professors and staff, personality traits of individuals and cultural spaces of the studied populations. That is why it is necessary to conduct such research in various universities to identify weaknesses and strengths. Universities need to improve the quality of educational services from the students' point of view by prioritizing and allocating budgets to the dimensions that have the highest gaps and reducing gaps.

Other findings of this study suggest that there is no significant difference between the dimensions of the quality of educational services and the field of study and gender of students. This shows that the field of study and gender does not affect the perceptions and expectations of the students of this university about the quality of educational services.

The results of the study of Hematinejad et al. (2014) (29) and Ghalavandi et al. (2012) (31) in terms of field of study were consistent with our study, but the result of the study of Khandan et al.(2015) (20) is inconsistent with our study and the reported significance difference between different fields of study and the quality of education services.

The findings of Khadem Rezaeian et al. (2016) (35), Khandan et al. (2015) (20), Hematinejad et al. (2014) (29) and Gorji et al. (2013) (6) do not show a significant difference in term of gender. This means that the quality of educational services is important for all male and female students, and they have the same view on the quality of educational services, which is consistent with the results of this study. The study of Rahimkhanli et al. (19) and Zahedi et al. (2015) (36) showed that the average score of negative gap between expectations and perceptions of male students is lower than female students, in 
fact the difference between expectations and perceptions of female students is higher than educational services, which is not in line with the results of our research.

According to the research results, it seems that there is a long way to go to achieve the optimal quality and eliminate this gap, and the training process in the dimensions of empathy, reliability, responsiveness, assurance, and tangibility needs to be improved. Therefore, it is suggested that according to the growing trend of student admission, students' opinions and views on the quality of educational services should be considered in order to improve the quality of educational services and reduce the gap between their perceptions and expectations. It should be noted that the identification of these gaps can be considered as a guide for educational planning and resource allocation and prioritization should be based on the maximum and minimum gaps announced for resource allocation. It is recommended that courses be held on effective teaching methods, communication skills and new teaching methods for university professors and staff. A system should be established for transferring students' suggestions and opinions to management and their opinions should be applied to educational programs. Timely and sufficient information in the field of educational activities should be provided and the management should determine some hours by to respond to students and facilitate access to advisor instructors and pay more attention to equipping the facilities of physical and educational spaces with new and up-to-date equipment.

\section{Limitations:}

The limitations of this study are cross-sectional study, census sampling method, use of questionnaire to collect data and inability to generalize to other fields of study in this university and other universities. This model only examines five factors and does not measure the quality of other university services such as libraries and information technology. Interventional, qualitative, and longitudinal studies are recommended for further studies; studies in research environments and disciplines different from the statistical population, and the use of other service quality assessment models are suggested.

\section{Declarations}

\section{Ethics approval and consent to participate:}

All methods were carried out in accordance with relevant guidelines and regulations. All experimental protocols were approved by Ethics Committee in Biomedical Research of Jiroft University of Medical Sciences (IR.JMU.REC.1397.50).

The purpose of the research was fully explained for participants. Research units were explained that if they desired, they could participate in the study and were not required to participate in the study (participating is freely optional), and that they could discontinue the study whenever they felt comfortable. Participants were assured that the information collected was confidential and that they did not need to mention their first and last names on the questionnaires or ID number and telephone number too. The research participants were explained that they would not be subject to any financial costs or damages. After fully explaining the objectives and conditions of entering the study, informed consent was obtained from the participants. The research results were provided to the research units and the authorities (if they wished). All those who contributed to the research were appreciated in publishing the final results of the research. In summary, Participants were fully informed about the research, duration of the study, confidentiality, and anonymity of the questionnaire, and voluntary participation in the study. Informed written consent was obtained from the participants.

\section{Consent for publication:}

Not applicable.

\section{Availability of data and materials:}

The datasets used and/or analyzed during the current study are availablefrom the corresponding authors on reasonable request. 


\section{Competing interests:}

The authors reported no conflict of interest.

\section{Funding:}

Self-funded.

\section{Authors' contributions:}

Foozieh R. performed the measurements , was involved in planning and supervised the work, Dastyar N. processed and performed the analysis, drafted the manuscript and designed the tabels. They wrote the manuscript with scientific support and helped supervise the project. Arbabisarjou A. involved in interpreting the results, worked on the manuscript and edited it. All authors discussed the results and commented on the manuscript. All authors read the final copy of manuscript and confirmed it for submission.

\section{Acknowledgments:}

Vice Chancellor for Research and Technology of Jiroft University of Medical Sciences and the sincere and sincere cooperation of the students in conducting this research are highly appreciated. This article is the result of a research project with code 174, which was approved on 15/1/2019, at the Jiroft University of Medical Sciences.

\section{Authors' information:}

Foozieh Rafati ${ }^{1}$, MSc. PhD

Azizollah Arbabisarjou ${ }^{2} . P h D$

Neda Dastyar ${ }^{3}$, RN, MSc

1-Email: foozieh1384@yahoo.com. Tell: 09133489902.

PO Box:7861763730. Address: Sabzevaran Square, Jiroft University of Medical Sciences, Jiroft, Kerman, Iran.

2 Email: arbabisarjou2007@gmail.com. Tell: 09153470005. PO Box:7861763730. Address: Mashahir Square, Zahedan University of Medical Sciences, Zahedan, Iran.

3*-Corresponding author: E.mail: nedadastyar98@gmail.com . Tell: +989193418943. P0 Box:7861763730. Address: Sabzevaran Square, Jiroft University of Medical Sciences, Jiroft, Kerman, Iran.

\section{References}

1. Rasoulabadi M, Shafieian M, Gharibi FM. Assessment of the quality of educational services by ehe servqual model: view points of the students at Kurdistan university of medical sciences. Journal of Kurdista university of medical sciences 2013;18(1):104-112. [Persian]

2. Parto S, Chehrzad MM, Asgari F, Kazemnezhad leili E. Educational Status and related factors of students of shahid beheshti nursing and midwifery school. Journal of shahid beheshti nursing and midwifery school; 2012. [Persian]

3. Bayraktaroglu G, Atrek B. Testing the superiority and dimensionality of sevequal vs. servperf in higher education. Journal of Quality management 2010;17(1): 47-59.

4. Stodnick M, Rogers P. Using sevqual to measure the quality of the classroom experience. Decision sciences Journal of innovative education 2008; 6(1): 115-133. 
5. Zafiropoulos C, Vrana V. Service quality assessment in a greek higher education institute. Journal of business economics and management 2008; 9(1): 33-45.

6. Gorji H, Tabatabaei S, Akbari A, Sarkhosh S, Khorasan S. Using the service quality gap's model(servqual) in imam Khomeini teaching hospital 2012. Journal of health administration 2013; 16(51): 7-18. [Persian]

7. Zareahmadabadi H, Arab M, Nasiri S, Hataminasab S, Bahrami M. Analysis of servqual in shahid sadoghi hospital, Yazd, Iran. Bimonthly Journal of hormozgan university of medical sciences 2012; 16(4): 333-340. [Persian]

8. Parasurman VA, Zeithmal Valaria A, Berry Leonard L. Servqual; amulti-item scale measuring consumer perceptions of service quality. Journal of retailing 1988; 64(1): 12-37.

9. AldarmahiA, Algahtani H, Alrabia M, Abuarab N, Shirah B. Determination of quality gap for educational services in undergraduate medical education. Saudi Med J 2019; 40 (6):595-601.

10. Faganel A. quality perception gap inside the higher education institution. International Journal of academic search 2010: 213-215.

11. Tofighi SH, Sadeghifar J, Hamouzadeh P, Afshari S, Forouzanfar F, Tagahavi shahri S. Quality of educational services from the viewpoints of students serqual model. Iranian Quarterly of education strategies 2011; 4(1): 21-26. [Persian]

12. Tavakoli N, Yadegarfar GH, Bagherian H, Ghasri F. Assessing the educational services quality of health information technology students. J Educ Health Promot 2019; 8: 168.

13. Banahene S, Ahudey E, Asamoah A. Analysis of SERVQUAL Application to Service Quality Measurement and Its Impact on Loyalty in Ghanaian Private Universities 2017; 8(4):18-33.

14. Zarei E, Ghazi Tabatabai S, Rahimi Forushani A, Rashidiyan A, Arab M. Hospital Services Quality From Patients' Point Of View: A Cross-Sectional Study In Tehran Private Hospitals. Journal of Tehran University of Medical Sciences 2011; 5(4): 66-76. [Persian]

15. Sabahifard Y, Ghafari M,Mohammadi M. Assessing the effect of quality of educational services on student satisfaction: Case study of Imam Sadegh University. Scientific-Research Quarterly 2017; 3(10): 147-162.

16. Khosravizade E, Zohrevandian K. Evaluating the quality of services of Arak University Sports Sciences Department based on Sevqual Combined Pattern. Journal of Research in Educational Sports 2017; 12: 37-60.

17. Yazdani B, Hajian M. Evaluating the quality of educational services in Isfahan universities based on the Servqual model. Scientific-Promotional Journal of Standard and Quality Management 2018; 8(1): 39-55.

18. Jafarinejad M, Ebrahimipour H, Lael-monfared E, Jamali Behnam F. Amini A. Quality of educational services from viewpoints of students at School of Public Health at Mashhad University of Medical Sciences...Journal of Medical Education and Development 2016;11(3): 247-259.

19. Rahim khanli M, Daneshmandi H, CHoobineh A. The students' viewpoint on the quality gap in educational services. J Adv Med Educ Prof 2014; 2(3):114-119.

20. Khandan M, Nouhi E, Sabzevari S. Quality Assessment of Educational Services in Nursing and Midwifery School of Kerman Based on SERVQUAL Model. Iranian Journal of Medical Education 2015: 15(32):252-262.

21. Nabilou B, Khorasani-Zavareh D. The Bridge Between Real and Ideal: Students Perception on Quality Gap in Reality and Their Educational Expectations. Iran Red Crescent Med J. 2014;16(9):e14254.

22. Donlagic, S, Fazlic S. Quality Assessment In Higher Education Using The Servqual Model.Management; 2015. 20(1): 39-57.

23. Asogwa E, Asadu U, Ezema U, Ugwu I, Ugwuanyi C. Use of ServQUAL in the Evaluation of Service Quality of Academic Libraries in Developing Countries. Library Philosophy and Practice 2015(ejournal- University of Nigeria - Nsukka).

24. Bradley RB. Analyzing Service Quality: The Case of Post-graduate Chinese Students 2006; Available From: http:/www.leeds.ac.uk/researchProgs/fileadmin/user_upload/documents. Accessed Apr 10, 2012. 
25. Gilavand A, Maraghi E. Assessing the Quality of Educational Services of Iranian Universities of Medical Sciences Based on the SERVQUAL Evaluation Model: A Systematic Review and Meta-Analysis. IJMS 2019; 44(4):273-284.

26. Yarmohammadian MH, Nazari M, Bahmanziari N, Moradi R, Mirzaei H, Navvabi E. Evaluation of Educational Services Quality for Healthcare Services Management Students of Isfahan University of Medical Sciences Based on Servqual Model. Iranian Journal of Medical Education 2015: 15(41):319-329.

27. Kavosi Z, Rahimi H, Qanbari P, Haidari L, Bahmaei J. Investigation of quality gap of educational services from the viewpoints of students of Shiraz University of Medical Sciences. Sadra Medical Science Journal. 2014; 2(2): 161-172.

28. Mukhopadhyay DK. Students' perception of quality of medical education in a medical college in west Bengal, India. Indian J Public Health 2016;60:4-9.

29. Hematinejhad Z, Hemattinejhad MA. Evaluating the quality of educational services of the Faculty of Physical Education and Science Gilan Sports Based on Servqual Model. Quarterly Journal of Studies Basics of management in sports 2014; 1(3): 11-28.

30. Yasbolaghi sharahi B, Havas beige F, Mosavipour S. Assessing the quality of educational services provided to Arak University students based on Servqual Model. Scientific-Research Journal of Education and Evaluation 2015; 8(30):29-44.

31. Ghalavandi H, Beheshti rad R, Ghaleyi A. Investigating the educational status of Urmia UniversityBased on the Seroqual model. the Quarterly Journal of Management and Development Process 2012; 25(3): 49-66.

32. Khademloo M, Fakhar M, Zare A. Survey of Service Quality Gap from the viewpoint of Para medicine Students in Mazandaran University of Medical Sciences. Journal of Ethics in Education 2013; 2 (1): 1-5.

33. Najafi R, Khorasani A, mohammadi R, Golovi M. Evaluate the quality of educational services Based on the Cervocal model. the Quarterly Journal of Geometry and Educational evaluation 2014;4(6):11-27.

34. Enayati T, Zameni F, Nasirpoor Deravi N. [Assessing the quality of educational service in Mazandaran University of Medical Sciences using Servqual Model]. Journal of health promotion Management. 2013; 2(2): 32-39.

35. Khadem rezaeian M, Mosavi bazaz SM. The gap in the quality of educational services based on the Servequal model Mashhad Medical School from the Students' Perspective. Scientific Quarterly Research School of Medicine, University of Medical Sciences and Services Shahid Beheshti Health Care 2016; 40(1):17-23.

36. Zahedi S. [Naghdi bar karborde modele SERVQUAL dar arzyabi khadamate amouzeshi daneshgahi: morede daneshkade mohandesi bargh va computer daneshgahe shahid beheshti]. The fifth conference of the quality of the university system, Tehran University Technical College; 2011. [cited 2015 August 30] Available from:

cuqa.ut.ac.ir/documents/30787/792815/21-Zahedi. 